\begin{tabular}{|c|l|}
\hline Title & In Situ Observation of Dynamic Meniscus Front Interface in A Ikal ine Fuel Cell \\
\hline Author(s) & Matsushima, Hisay oshi; Majima, W ataru; Fukunaka, Y asuhiro; Ueda, Mikito \\
\hline Citation & $\begin{array}{l}\text { ECS electrochemistry letters, 4(7), F43-F45 } \\
\text { https://doi.org/40.1149/2.0031507eel }\end{array}$ \\
\hline Issue Date & 2015-05-06 \\
\hline Doc URL & http://hdl.handle.net/2115/59577 \\
\hline Rights(URL) & http://creativecommons.org/icenses/by/4.0/ \\
\hline Type & article \\
\hline File Information & Matsushima.pdf \\
\hline
\end{tabular}

Instructions for use 


\title{
In Situ Observation of Dynamic Meniscus Front Interface in Alkaline Fuel Cell
}

\author{
Hisayoshi Matsushima, ${ }^{\mathrm{a}, \mathrm{z}}$ Wataru Majima, ${ }^{\mathrm{b}}$ Yasuhiro Fukunaka, ${ }^{\mathrm{b}, *}$ and Mikito Ueda ${ }^{\mathrm{a}, * *}$ \\ ${ }^{a}$ Faculty of Engineering, Hokkaido University, Sapporo, Hokkaido 060-8628, Japan \\ ${ }^{b}$ Graduate School of Energy Science, Kyoto University, Sakyo-ku, Kyoto 606-8501, Japan
}

Controlling the wetting properties at the three-phase interface is important for improving the performance of alkaline fuel cells. The meniscus of a potassium hydroxide droplet was formed on a nickel electrode, and the interference fringe during the oxygen reduction reaction was observed by confocal laser microscopy. The high spatial resolution of the microscope revealed thin film formation at the meniscus front interface. The thickness decreased with increasing cathodic potential. The generation of microscopic convection by interfacial surface tension may affect mass transfer in the thin film.

(c) The Author(s) 2015. Published by ECS. This is an open access article distributed under the terms of the Creative Commons Attribution 4.0 License (CC BY, http://creativecommons.org/licenses/by/4.0/), which permits unrestricted reuse of the work in any medium, provided the original work is properly cited. [DOI: 10.1149/2.0031507eel] All rights reserved.

Manuscript submitted March 23, 2015; revised manuscript received April 27, 2015. Published May 6, 2015.

Electrochemical devices, such as water electrolysis equipment and fuel cells, have been studied for realizing the hydrogen economy. ${ }^{1}$ Systems using alkaline media are promising because they do not require a noble metal catalyst or special corrosion-resistant materials. Therefore, alkaline electrolysis ${ }^{2-4}$ and fuel cells ${ }^{5-7}$ have been investigated for hydrogen production and power generation, respectively.

Alkaline fuel cells (AFCs) have attracted attention since they were used in the Apollo space program in the 1960 s. ${ }^{8}$ Recently, the development of alkaline membranes has opened up the possibility of miniaturized AFCs that can be embedded in electric devices. ${ }^{9,10}$

The gas diffusion electrode (GDE) in AFCs is a key structure for controlling cell performance. When gas molecules reach the meniscus in the GDE, they dissolve at the gas/electrolyte interface, diffuse to the electrode surface, and finally undergo the electrochemical reaction at the liquid/solid interface. Selman et al. have actively investigated the effect of meniscus geometry on fuel cell reactions. ${ }^{11-12}$ The thin film interface was measured optically, and the film geometry was very sensitive to interfacial energies. ${ }^{13-16}$ Muller investigated the geometric properties of meniscus, ${ }^{15}$ but the detailed dynamic motions of the meniscus on a polarized electrode remained unclear.

The CCD images in our previous paper demonstrated the dynamic behavior of the contact angle during the oxygen reduction reaction (ORR) in AFCs on a macroscopic scale. ${ }^{17,18}$ The results suggested that the wettability at the three phase interface depended strongly on the electrode potential. However, the dynamic behavior on the microscopic scale could not be discussed because the front part of the meniscus could not be measured accurately with only a CCD camera. In the present study, we employed a confocal laser microscope and in-situly investigated the dynamic effects of the meniscus on the polarization.

\section{Experimental}

The electrochemical apparatus and method have been described in our previous paper. ${ }^{18}$ Briefly, the cathode electrode was a nickel disc ( $\phi 42 \mathrm{~mm} \times 0.1 \mathrm{~mm}, 99.99 \%$, Nilaco Corp.) and the anode was a palladium-hydrogen electrode $(\phi 4 \mathrm{~mm} \times 0.1 \mathrm{~mm}, 99.99 \%$, Nilaco Corp.). The center of the nickel disc was perforated, and a palladium wire was attached at the perforation. The nickel electrode was polished with $1.0,0.3$, and $0.05 \mu \mathrm{m}$ alumina powder. The platinum wire ( $\phi 0.5 \mathrm{~mm}, 99.99 \%$, Nilaco Corp.) was used as a reference electrode. Prior to the measurements, all electrodes were ultrasonically cleaned in ethanol and purified water for 5 min each. The electrolyte was an aqueous potassium hydroxide solution (4.5 M, Wako Pure Chemical Industries). Oxygen gas was bubbled through the electrolyte for $2 \mathrm{~h}$.

\footnotetext{
*Electrochemical Society Fellow.

** Electrochemical Society Active Member.

${ }^{\mathrm{z}}$ E-mail: matsushima@eng.hokudai.ac.jp
}

Electrochemical measurements (HZ-3000, Hokuto Denko Corp.) were performed in the potentiostatic mode for $600 \mathrm{~s}$ at $298 \mathrm{~K}$. Pure oxygen gas was introduced at a flow rate of $100 \mathrm{~mL} \mathrm{~min}^{-1}$ to exclude carbon dioxide. The front part of the meniscus was observed by confocal laser scanning microscopy (VK-X100, Keyence) with a helium-neon laser $(633 \mathrm{~nm})$

\section{Results and Discussion}

We formed a droplet $(200 \mu \mathrm{l})$ of aqueous potassium hydroxide on the electrode. The meniscus front interface crept outward as soon as the reaction started. Due to the formation of a thin liquid film, the interference fringes appeared around the meniscus front, as shown in Fig. 1. Although some black and white noise spots were created by dust on the lens and mirror, the fringe was clearly detected. The
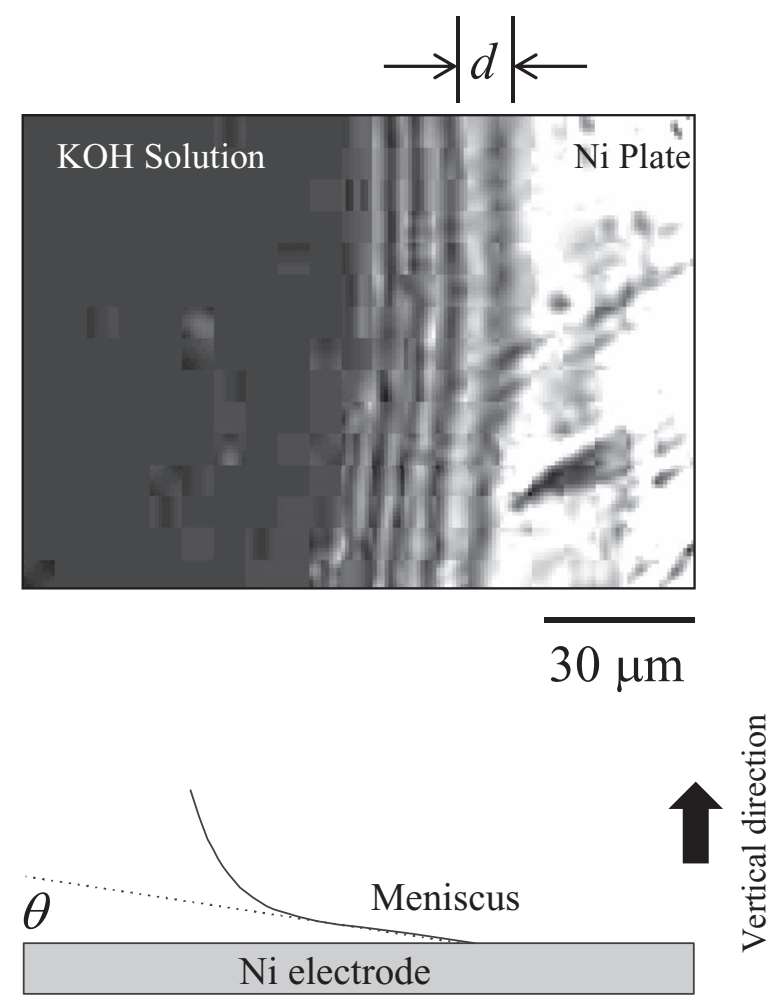

Figure 1. Confocal laser microscope image of the interference fringe at the meniscus of a droplet of potassium hydroxide on a nickel electrode during the ORR. 


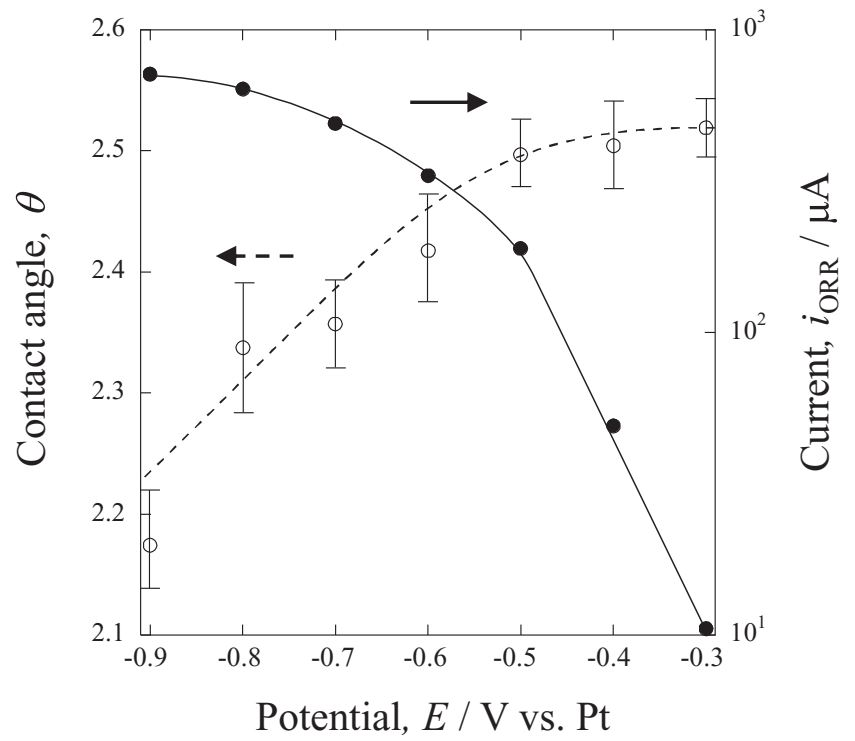

Figure 2. Comparison of the contact angle, $\theta$, of the droplet, and the ORR current, $i_{\mathrm{ORR}}$, as a function of electrode potential.

fringe kept moving for a few minutes during the ORR. Here, distance $d$ is defined as the distance between the first and second fringes (Fig. 1). The contact angle, $\theta$, is estimated from the equation, $\tan \theta=$ $h / d$ where the interval is the same as the half-wavelength gap, $2 / \lambda$, and $h$ is thickness of the meniscus. ${ }^{19}$

Figure 2 shows the value of $\theta$ at each electrode potential. The error bars mean the standard deviation of four times experiments. Even in the consideration of the experimental errors, Fig. 2 demonstrates the significant dependency of $\theta$ on the potential. The angles were much smaller than those in our previous results, ${ }^{17,20}$ because the macroscopic observation made it difficult to observe the thin liquid film $(<1 \mu \mathrm{m})$. The angle was in the range of $2.1^{\circ}$ to $2.5^{\circ}$, meaning that the thin liquid layer was around $25 \mathrm{~nm}$ thick. The angle was almost $2.5^{\circ}$ at $-0.5 \mathrm{~V} \leq$ $E \leq-0.3 \mathrm{~V}$, whereas it decreased to $2.1^{\circ}$ when the potential decreased $(E<-0.5 \mathrm{~V})$.

Correspondingly, the ORR current, $i_{\mathrm{ORR}}$, depended on the potential in Fig. 2. The ORR current in the potential range from -0.3 to $-0.5 \mathrm{~V}$ could be fitted with a Tafel slope. The slope was $0.14 \mathrm{~V} \mathrm{dec}^{-1}$, which was in good agreement with a previously reported value $(0.13 \mathrm{~V}$ $\left.\mathrm{dec}^{-1}\right){ }^{21}$ The fitting line diverged from the Tafel relation at more cathodic potentials $(\leq-0.5 \mathrm{~V})$, which could be explained by the mass-transfer limitation. The dissolution of oxygen gas at the air/liquid interface or the diffusion of dissolved oxygen was probably the ratedetermining factor. $^{22}$

The time variation of $i_{\mathrm{ORR}}$ in Fig. 3 indicates a mass-transfer limited reaction. Thus, the current reached a constant value as soon as electrolysis started at -0.3 and $-0.5 \mathrm{~V}$, whereas the current at more cathodic potentials sharply decreased for a few seconds due to the consumption of the dissolved gas by the ORR. The value of $i_{\mathrm{ORR}}$ reached a minimum value at $10-150 \mathrm{~s}$ and it increased until the end of the measurements. The dynamic motion of the meniscus mainly contributed to the increase of $i_{\mathrm{ORR}}$ because the apparent reaction area was enlarged. As a reference point, the time at which the fringe motion stopped is indicated with an arrow in Fig. 3. Corresponding to the current behavior, the contact angle of $\theta$ was significantly decreased until the arrow point. ${ }^{17,18}$

Although the meniscus size was stable in the region beyond the arrow in Fig. 3, the current increased with time at -0.7 and $-0.9 \mathrm{~V}$. This might be attributed to several fluid effects such as Marangoni convection around the gas/liquid/solid three-phase interface. ${ }^{23,24}$ This convection may help stir the solution in the thin layer. The electrochemical reaction induces a significant concentration gradient in the vertical direction of the electrode surface, especially under the mass-

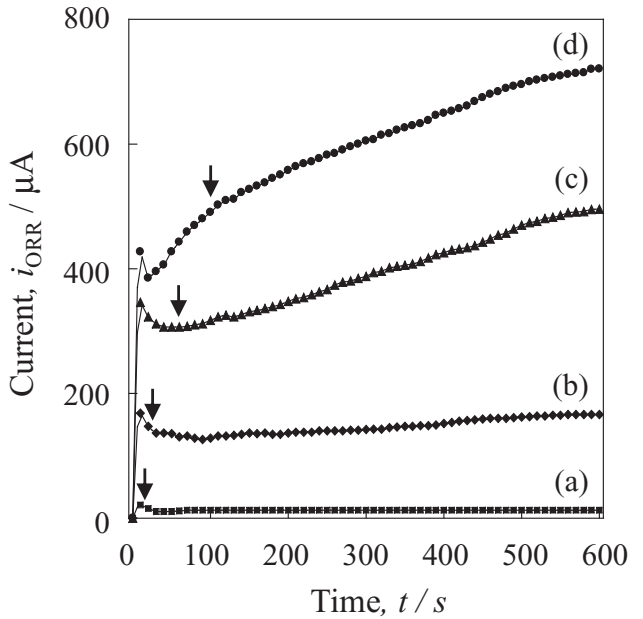

Figure 3. Transient behavior of the ORR current at potentials of (a) -0.3 , (b) -0.5 , (c) -0.7 , and (d) $-0.9 \mathrm{~V}$. Arrows indicate the time at which the meniscus motion stopped.

transfer limitation. Because the interfacial tension force is determined by the dissolved gas concentration, microscopic convection is induced by the difference in the concentration near the meniscus front. ${ }^{25}$ In the same manner, the temperature gradient force might also induce convection. ${ }^{26}$ Because the ORR occurs inhomogeneously on the electrode surface, the current is centralized at the front of the meniscus, and a temperature gradient exists along the electrode surface.

\section{Conclusions}

The confocal laser microscopy demonstrated the very thin meniscus layer $(<25 \mathrm{~nm})$ during ORR. The contact angle decreased from $2.5^{\circ}$ to $2.1^{\circ}$ with increasing cathodic potential. As soon as starting the reduction reaction, the ORR current was decreased by the mass transfer limitation of the dissolved oxygen gas, while it gradually increased after $100 \mathrm{~s}$. This was attributed to the droplet motion that enlarged the reaction area. Moreover, the generation of microscopic convection by interfacial surface tension would enhance the mass transfer in the meniscus.

\section{Acknowledgment}

The authors appreciate financial support from Inamori Foundation in Japan.

\section{References}

1. N. Armaroli and V. Balzani, ChemSusChem, 4, 21 (2011).

2. P. Mandin, Z. Derhoumi, H. Roustan, and W. Rolf, Electrochim. Acta, 128, 248 (2014).

3. A. Manabe, M. Kashiwase, T. Hashimoto, T. Hayashida, A. Kato, K. Hirao, I. Shimomura, and I. Nagashima, Electrochim. Acta, 100, 249 (2013).

4. K. Zeng and D. K. Zhang, Prog. Energy Combust. Sci., 36, 307 (2010).

5. F. Bidault, D. J. L. Brett, P. H. Middleton, N. Abson, and N. P. Brandon, Int. J. Hydro. Energy, 35, 1783 (2009).

6. H. Meng and P. K. Shen, Electrochem. Commun., 8, 588 (2006).

7. G. F. Mclean, T. Niet, S. P. Richard, N. Djilali, and N. Int. J. Hydro. Energy, 27, 507 (2002).

8. R. J. Davenport, F. H. Schubert, and D. J. Grigger, J. Power Sources, 36, 235 (1991).

9. X. Wu and K. Scott, J. Power Sources, 206, 14 (2012).

10. G. K. S. Prakash, F. C. Krause, F. A. Viva, S. R. Narayanan, and G. A. Olah, J. Power Sources, 196, 7967 (2011).

11. J. R. Selman and P. H. Hsieh, Int. J. Hydrog. Energy, 37, 19270 (2012).

12. S. G. Hong and J. R. Selman, J. Electrochem. Soc., 151, A77 (2004).

13. M. Inaba, M. Uno, J. Maruyama, A. Tasaka, K. Katakura, and Z. Ogumi, J. Electroanal. Chem., 417, 105 (1996).

14. J. O. Bockris and B. D. Cahan, J. Chemical Physics 50, 1307 (1969).

15. R. H. Muller, J. Electrochem. Soc., 113, 943 (1966).

16. D. N. Bennion and C. W. Tobias, J. Electrochem. Soc., 113, 589 (1966)

17. W. Majima, H. Matsushima, Y. Fukunaka, and M. Ueda, J. Electrochem. Soc., 161, F1002 (2014). 
18. H. Matsushima, W. Majima, and Y. Fukunaka, Electrochim. Acta, 114, 509 (2013).

19. C. Y. K. Fung, R. Sedev, and J. N. Connor, Adv. Powder Technol., 25, 1171 (2014).

20. H. Matsushima, Y. Fukunaka, and K. Kuribayashi, Electrochim. Acta, 20, 4190 (2006).

21. M. Ma, V. S. Donepudi, G. Sandi, Y. K. Sun, and J. Prakash, Electrochim. Acta, 49 , 4411 (2004).
22. T. Suzuki, K. Kudo, and Y. Morimoto, J. Power Sources, 222, 379 (2013).

23. Z. H. Pan, S. Dash, J. A. Weibel, and S. V. Garimella, Langmuir, 29, 15831 (2013).

24. Z. Derhoumi, Ph. Mandin, R. Wuthrich, and H. Roustan, Journal of Applied Fluid Mechanics, 4, 81 (2011)

25. S. Lubetkin, Electrochim. Acta, 48, 357 (2002)

26. H. Kasumi, P. J. Sides, and J. L. Anderson, J. Colloid Interface Sci., 276, 239 (2004). 